\title{
Outcome prediction following transcatheter aortic valve implantation: Multiple risk scores comparison
}

\author{
Karol Zbroński ${ }^{1}$, Zenon Huczek ${ }^{1}$, Dominika Puchta ${ }^{1}$, Katarzyna Paczwa ${ }^{1}$, \\ Janusz Kochman ${ }^{1}$, Radosław Wilimski ${ }^{2}$, Piotr Scisło ${ }^{1}$, Bartosz Rymuza ${ }^{1}$, \\ Krzysztof J. Filipiak ${ }^{1}$, Grzegorz Opolski ${ }^{1}$ \\ ${ }^{1} 1^{\text {st }}$ Department of Cardiology, Medical University of Warsaw, Poland \\ ${ }^{2}$ Department of Cardiac Surgery, Medical University of Warsaw, Poland
}

\begin{abstract}
Background: The aim of the study was to compare 7 available risk models in the prediction of 30-day mortality following transcatheter aortic valve implantation (TAVI). Heart team decision supported by different risk score calculations is advisable to estimate the individual procedural risk before TAVI.
\end{abstract}

Methods: One hundred and fifty-six consecutive patients ( $n=156,48 \%$ female, mean age $80.03 \pm 8.18$ years) who underwent TAVI between March 2010 and October 2014 were included in the study. Thirty-day follow-up was performed and available in each patient. Baseline risk was calculated according to EuroSCORE I, EuroSCORE II, STS, ACEF, Ambler's, OBSERVANT and SURTAVI scores.

Results: In receiver operating characteristics analysis, neither of the investigated scales was able to distinguish between patients with or without an endpoint with areas under the curve (AUC) not exceeding 0.6, as follows: EuroSCORE I, AUC 0.55; 95\% confidence intervals (CI) 0.47-0.63, $p=0.59$; EuroSCORE II, AUC 0.59; 95\% CI 0.51-0.67, $p=0.23$; STS, AUC 0.55; 95\% CI 0.47-0.63, $p=0.52 ; A C E F, A U C$ 0.54; 95\% CI 0.46-0.62, $p=0.69 ;$ Ambler's, AUC 0.54; 95\% CI 0.46-0.62, $p=0.70$; OBSERVANT, AUC 0.597; 95\% CI 0.52-0.67, $p=0.21$; SURTAVI, AUC 0.535; 95\% CI 0.45-0.62, $p=0.65$. SURTAVI model was calibrated best in high-risk patients showing coherence between expected and observed mortality (10.8\% vs. $9.4 \%$, $p=0.982)$. ACEF demonstrated best classification accuracy $(17.5 \%$ vs. $6.9 \%, p=0.053$, observed mortality in high vs. non-high-risk cohort, respectively).

Conclusions: None of the investigated risk scales proved to be optimal in predicting 30-day mortality in unselected, real-life population with aortic stenosis referred to TAVI. This data supports primary role of heart team in decision process of selecting patients for TAVI. (Cardiol J 2016; 23, 2: 169-177)

Key words: transcatheter aortic valve implantation, aortic stenosis, risk prediction

Address for correspondence: Karol Zbroński, MD, $1^{\text {st }}$ Department of Cardiology, Medical University of Warsaw, ul. Banacha 1a, 02-097 Warszawa, Poland, e-mail: karol.zbronski@gmail.com 


\section{Introduction}

Transcatheter aortic valve implantation (TAVI) is a procedure designed for inoperable or high-risk patients with severe aortic stenosis (AS). According to European guidelines, the heart team should make the decision whether a patient is not suitable for conventional surgical replacement (aortic valve replacement) and therefore should undergo TAVI [1]. Two risk scores have been suggested as a possible aid to heart team's decision - logistic European System for Cardiac Operative Risk Evaluation (EuroSCORE) $>20 \%$ and The Society of Thoracic Surgeons's (STS) score $>10 \%$. Both risk scores have been developed and validated in surgical settings and are believed to either overestimate or underestimate mortality, respectively [2-4]. Recently, a number of new risk scores or models have been developed, some of them based on surgical patients (EuroSCORE II, age-creatinine-ejection fraction [ACEF], Ambler's risk score) [5-7], other on those undergoing TAVI (OBSERVANT, SURTAVI model) $[8,9]$. There is few data comparing performance of multiple risk stratification models in unselected population of TAVI patients. Therefore, the aim of this study was to compare seven available risk models - logistic EuroSCORE, EuroSCORE II, STS, ACEF, Ambler's, OBSERVANT and SURTAVI — in the prediction of 30-day mortality following TAVI.

\section{Methods}

\section{Study design and population}

From March 2010 to October 2014, 156 consecutive, inoperable or high-risk patients $(\mathrm{n}=156$, $48 \%$ female, mean age of $80.03 \pm 8.18$ years) with severe symptomatic AS (aortic valve area $<1.0 \mathrm{~cm}^{2}$, or indexed valve area less than $0.6 \mathrm{~cm}^{2} / \mathrm{m}^{2}$, or mean gradient $>40 \mathrm{~mm} \mathrm{Hg}$, or maximum jet velocity $>4.0 \mathrm{~m} / \mathrm{s}$, or velocity ratio $<0.25$ ), after heart team decision treated with TAVI, were prospectively enrolled. Both, balloon$\left(\right.$ Edwards Sapien ${ }^{\circledR}$ ) and self-expandable (CoreValve $^{\circledR}$, Medtronic) aortic valve prostheses were used and all standard delivery routes were applied. It was an all-comers study and no exclusion criteria were used. Informed consent was obtained from all participating patients and local Ethics Committee granted permission for the study.

Predicted mortality was calculated according to logistic EuroSCORE [2], EuroSCORE II [5], STS [3], Ambler's [6], ACEF [7] and OBSERVANT [9] scores. In case of SURTAVI [8] model, patients were categorized straightaway into three groups
- low, intermediate and high risk - due to lack of proper formula or calculator enabling continuous risk calculation. In the remaining 6 risk scores - patients were subdivided into tertiles of low, intermediate or high risk, based on their predicted mortality in each scale. Afterwards, for each scale predicted and observed mortality of patients from high-risk group were compared to predicted and observed mortality of non-high-risk group (pooled low- and intermediate-risk groups).

\section{Risk scores characteristics}

In the present study, besides established and recognized scales predicting 30-day mortality, used in Europe and North America, namely logistic EuroSCORE and STS score, newer and less validated models were implemented.

Logistic EuroSCORE [2] takes into consideration the same 17 risk factors as its predecessor — additive EuroSCORE [10] — a risk model that was designed to predict early mortality after major cardiac surgery - with additional logistic regression analysis aiming to provide more accurate risk predictions in high-risk patients. Original model was developed and validated in 1999 on a dataset of more than 13,000 patients.

EuroSCORE II [5], based upon data from 22,000 patients and characterized by better calibration and similar discrimination power in predicting early mortality after cardiac surgery, replaced original EuroSCORE in 2011. It includes 18 factors.

The 2008 STS' risk model [3] was conceived in order to assess early postoperative course after coronary artery bypass grafting (CABG), valve surgery or both. It is by far the most complex model taking into consideration 39 factors, developed and validated based upon data from almost 975,000 patients and providing estimations on early mortality as well as early complications including stroke, renal failure or prolonged ventilation.

Ambler's score is a risk model created in order to assess early mortality after aortic and/or mitral valve surgery with or without concomitant CABG. It was developed and validated in 2005 [6] based upon a dataset from almost 33,000 patients and consists of 14 factors.

ACEF was also designed as an early postoperative mortality estimation tool. Its authors have made an effort to substantially limit the number of included factors - to only 3 - in order to facilitate its clinical application. Published in 2009 [7], developed and validated on almost 9,000 patients, it has proven to offer similar accuracy and calibration as established risk models when applied to patients undergoing elective cardiac surgery. 
SURTAVI model is a 10 -factor risk stratification system proposed in 2012 in order to estimate early mortality in patients undergoing TAVI as part of "SURgical replacement and Transcatheter Aortic Valve Implantation" (SURTAVI) trial [8].

OBSERVANT is also a risk model designed specifically for TAVI procedures. Published in 2014, developed and validated based upon data from 1,900 TAVI patients, it takes into consideration 7 factors. In the original study [9], it managed to offer better calibration and accuracy than logistic EuroSCORE with equally good discrimination.

Detailed list of elements constituting the global risk in respective scales is presented in Table 1.

\section{Data collection and endpoints}

Based on pre-procedural evaluation charts, predicted mortality was calculated for respective models. Thirty days after the procedure each living patient was readmitted for scheduled echocardiographic assessment. In case of death occurrence between discharge from index hospitalization and 30-day scheduled admission, source documentation was obtained. Primary endpoint of the study was the assessment of discriminating abilities of respective risk models in terms of 30-day mortality. Secondary endpoints were the calibration of the scales in high-risk vs. non high-risk subpopulations and comparison of their classification accuracy.

\section{Statistical analysis}

Continuous variables, expressed as means \pm standard deviation, were compared using Student's t-test. Categorical variables, expressed as counts and percentages, were compared using $\chi^{2}$ test or Fisher's exact test, as appropriate.

Receiver operating characteristic (ROC) analysis, producing an area under the curve (AUC) (c statistic) with 95\% confidence intervals (CI), was used for discrimination of the predictive scores of 30-day mortality. Calibration (ability to match patients' expected vs. observed mortality) was determined by binomial testing of expected vs. observed 30-day mortality. Classification accuracy was assessed by comparison of survival curves of high and non-high risk groups (log-rank test).

All probability values reported are 2 -sided and a value $<0.05$ was considered to be significant. All data were processed using the MedCalc Software, version 15.2.2 (MedCalc Software, Ostend, Belgium).

\section{Results}

\section{Baseline characteristics}

Detailed characteristics of the study population are presented in Table 2 . In total, $48.1 \%$ of patients were female $(\mathrm{n}=75)$ and $23.7 \%$ were over 85 years old $(n=37)$. The minority of patients had left ventricular ejection fraction $(\mathrm{LVEF})<40 \%(\mathrm{n}=29,18.6 \%)$ and $91(58.3 \%)$ patients had admission glomerular filtration rate (GFR) lower than $60 \mathrm{~mL} / \mathrm{min} / \mathrm{m}^{2}$. Non-transfemoral access was used in $35(22.4 \%)$ patients and self-expandable valve prosthesis were preferred $(\mathrm{n}=98,62.8 \%)$.

\section{Mortality}

Thirty-day follow-up was complete and available in all patients $(100 \%)$. There were $15(9.6 \%)$ patients who died within 30 days after the procedure or later if the patient was not discharged after 30 days. Majority of deaths occurred within first 2 days after the procedure $(\mathrm{n}=9,5.8 \%)$ and were cardiac-related (Fig. 1). Univariate analysis of possible predictive factors of early mortality demonstrated no impact of age, gender, LVEF, type of prosthesis, chosen approach, nor pulmonary hypertension on early mortality (Table 2). However, mitral regurgitation $(\mathrm{MR}) \geq 3$ diagnosed at baseline and chronic kidney disease (GFR $<30 \mathrm{~mL} / \mathrm{min} / 1.73 \mathrm{~m}^{2}$ ) occurred significantly more frequently in patients who died $(\mathrm{p}=0.036$ and $\mathrm{p}=0.04$, respectively). Severe aortic regurgitation (AR) immediately after TAVI was also found more often in patients who died ( $20 \%$ vs. $4.3 \%, \mathrm{p}=0.04)$.

\section{Discriminating abilities of risk models}

In ROC analysis, neither of the investigated scales was able to distinguish between patients with or without an endpoint, with c-statistic not exceeding 0.6, as follows: logistic EuroSCORE I, AUC 0.55, 95\% CI 0.47-0.63, p = 0.59; EuroSCORE II, AUC 0.59, 95\% CI 0.51-0.67, $\mathrm{p}=0.23$; STS, AUC 0.55, 95\% CI 0.47-0.63, p = 0.52; ACEF, AUC 0.54, 95\% CI 0.46-0.62, $\mathrm{p}=0.69$; Ambler's, AUC $0.54,95 \%$ CI $0.46-0.62, \mathrm{p}=0.70$; OBSERVANT, AUC 0.597, 95\% CI 0.52-0.67, $\mathrm{p}=0.21$; SURTAVI, AUC 0.535, 95\% CI 0.45-0.62, $\mathrm{p}=0.65$. Figure 2 demonstrates comparison of risk models' ROC. 
Table 1. Presentation of risk factors in respective risk stratification models.

\begin{tabular}{|c|c|c|c|c|c|c|c|}
\hline & $\begin{array}{c}\text { Euro- } \\
\text { SCORE I }\end{array}$ & $\begin{array}{l}\text { Euro- } \\
\text { SCORE II }\end{array}$ & STS & ACEF & Ambler's & OBSERVANT & SURTAVI \\
\hline \multicolumn{8}{|l|}{ Patient characteristics } \\
\hline Age & + & + & + & + & + & & \\
\hline Sex & + & + & + & & + & & \\
\hline Height & & & + & & & & \\
\hline Weight & & & + & & & & \\
\hline Body mass index & & & & & + & & \\
\hline Ethnicity & & & + & & & & \\
\hline \multicolumn{8}{|l|}{ Co-morbid conditions } \\
\hline Diabetes & & + & + & & & + & + \\
\hline Hypertension & & & + & & + & & \\
\hline Chronic lung/pulmonary disease & + & + & + & & & & + \\
\hline Extracardiac arteriopathy & + & + & + & & & & \\
\hline Peripheral vascular disease & & & + & & & & + \\
\hline Neurological dysfunction & + & & + & & & & + \\
\hline Frailty & & & & & & & + \\
\hline Cerebrovascular accident & & & + & & & & \\
\hline Creatinine clearance & & + & & & & + & + \\
\hline Serum creatinine & + & & + & + & + & & \\
\hline Dialysis-dependent renal failure & & & + & & + & & \\
\hline Immunosuppressive therapy & & & + & & & & \\
\hline Poor mobility & & + & & & & & \\
\hline \multicolumn{8}{|l|}{ Cardiac history } \\
\hline NYHA classification & & + & + & & & + & \\
\hline Unstable angina & + & & + & & & & \\
\hline CCS class IV angina & & + & & & & & \\
\hline Recent myocardial infarction & + & + & + & & & & \\
\hline Arrhythmias & & & + & & + & & \\
\hline Previous cardiac surgery & + & + & & & + & & + \\
\hline Previous CABG & & & + & & & & \\
\hline Previous valvular disease & & & + & & & & \\
\hline Previous PCl & & & + & & & & \\
\hline Previous balloon aortic valvuloplasty & & & & & & + & \\
\hline Active endocarditis & + & + & + & & & & \\
\hline Number of diseased coronary vessels & & & + & & & & \\
\hline Type and severity of valvular disease & + & & & & & & \\
\hline \multicolumn{8}{|l|}{ Hemodynamic state } \\
\hline Pulmonary hypertension & + & + & & & & + & + \\
\hline Ejection fraction & + & + & + & + & + & + & + \\
\hline Critical preoperative state & + & + & & & & + & \\
\hline Cardiogenic shock & & & + & & & & \\
\hline Resuscitation & & & + & & & & \\
\hline Inotropic agents & & & + & & & & \\
\hline Intra-aortic balloon pump & & & + & & & & \\
\hline \multicolumn{8}{|l|}{ Procedure } \\
\hline Emergency & + & + & + & & & & \\
\hline Surgery on thoracic aorta & + & + & + & & & & \\
\hline Aortic valve surgery & & + & + & & + & & \\
\hline Mitral valve surgery & & & + & & + & & \\
\hline Aortic and mitral valve surgery & & & + & & + & & \\
\hline Tricuspid valve surgery & & & + & & & & \\
\hline Surgery for CHD & & & + & & & & \\
\hline Rhythmological surgery & & & + & & & & \\
\hline Concomitant CABG & & & + & & + & & \\
\hline Concomitant tricuspid valve surgery & & & + & & + & & \\
\hline Post-infarct septal rupture & + & & & & & & \\
\hline
\end{tabular}

CABG - coronary artery by-pass grafting; CCS - Canadian Cardiovascular Society; CHD — congenital heart disease; NYHA — New York Heart Association; $\mathrm{PCl}$ - percutaneous coronary intervention; TAVI — transcatheter aortic valve implantation 
Table 2. Demographics, baseline and procedural characteristics.

\begin{tabular}{|c|c|c|c|c|}
\hline & $\begin{array}{c}\text { Overall population } \\
\quad(n=156)\end{array}$ & $\begin{array}{l}\text { Patients who } \\
\text { died ( }=15)\end{array}$ & $\begin{array}{c}\text { Patients who } \\
\text { survived }(n=141)\end{array}$ & $\mathbf{P}$ \\
\hline \multicolumn{5}{|l|}{ Demographics } \\
\hline Female gender & $75(48.1 \%)$ & $5(33.3 \%)$ & $70(49.6 \%)$ & 0.35 \\
\hline Age [years] & $80.03 \pm 8.18$ & $77.75 \pm 10.15$ & $80.28 \pm 7.95$ & 0.26 \\
\hline \multicolumn{5}{|l|}{ Baseline characteristics } \\
\hline Body mass index [kg/m²] & $27.07 \pm 4.21$ & $26.54 \pm 1.22$ & $27.13 \pm 4.41$ & 0.23 \\
\hline Hypertension & $111(71.2 \%)$ & $11(73.3 \%)$ & $100(70.9 \%)$ & 0.92 \\
\hline Diabetes & $58(37.2 \%)$ & $5(33.3 \%)$ & $53(37.6 \%)$ & 0.97 \\
\hline $\mathrm{GFR}<30 \mathrm{~mL} / \mathrm{min}$ & $15(9.6 \%)$ & $4(26.7 \%)$ & $11(7.8 \%)$ & 0.04 \\
\hline Hemodialysis & $7(4.5 \%)$ & $2(13.3 \%)$ & $5(3.5 \%)$ & 0.14 \\
\hline Previous $\mathrm{PCl}$ & $58(37.4 \%)$ & $4(26.7 \%)$ & $54(38.6 \%)$ & 0.42 \\
\hline Previous CABG & $15(9.6 \%)$ & $1(6.7 \%)$ & $14(9.9 \%)$ & 1 \\
\hline Recent myocardial infarction & $17(10.9 \%)$ & $1(6.7 \%)$ & $16(11.3 \%)$ & 0.91 \\
\hline History of stroke/TIA & $22(14.1 \%)$ & $1(6.7 \%)$ & $21(14.9 \%)$ & 0.63 \\
\hline Atrial fibrillation & $56(35.9 \%)$ & $3(20.0 \%)$ & $53(37.6 \%)$ & 0.29 \\
\hline Chronic obstructive pulmonary disease & $28(17.9 \%)$ & $2(13.3 \%)$ & $26(18.4 \%)$ & 0.89 \\
\hline Pulmonary hypertension & $11(7.1 \%)$ & $1(6.7 \%)$ & $10(7.1 \%)$ & 1 \\
\hline Osteoporosis & $6(3.8 \%)$ & $2(13.3 \%)$ & $4(2.8 \%)$ & 0.10 \\
\hline Peripheral artery disease & $27(17.3 \%)$ & $4(26.7 \%)$ & $23(16.3 \%)$ & 0.52 \\
\hline NYHA class IV & $10(6.4 \%)$ & $1(6.7 \%)$ & $9(6.4 \%)$ & 1 \\
\hline MR grade $\geq 3$ & $20(12.8 \%)$ & $5(33.3 \%)$ & $15(10.6 \%)$ & 0.04 \\
\hline LVEF [\%] & $50.69 \pm 14.11$ & $49.80 \pm 19.79$ & $50.78 \pm 13.46$ & 0.85 \\
\hline Hemoglobin $[\mathrm{g} / \mathrm{dL}]$ & $12.17 \pm 1.62$ & $12.18 \pm 1.01$ & $12.17 \pm 1.67$ & 0.99 \\
\hline Platelets $\left[\times 10^{9} / L\right]$ & $201.22 \pm 65.7$ & $185.7 \pm 54.3$ & $202.88 \pm 66.7$ & 0.34 \\
\hline Mean pressure gradient [mm Hg] & $49.10 \pm 15.47$ & $48.33 \pm 16.71$ & $49.18 \pm 15.39$ & 0.84 \\
\hline \multicolumn{5}{|l|}{ Procedural data } \\
\hline Non-transfemoral access & $35(22.4 \%)$ & $5(33.3 \%)$ & $30(21.3 \%)$ & 0.46 \\
\hline Self-expandable prosthesis & $98(62.8 \%)$ & $10(66.7 \%)$ & $88(62.4 \%)$ & 0.97 \\
\hline Procedure time [min] & $207.5 \pm 54.7$ & $220.5 \pm 59.1$ & $206.12 \pm 54.2$ & 0.34 \\
\hline Fluoroscopy time [min] & $31.8 \pm 12.6$ & $30.8 \pm 12.5$ & $31.9 \pm 12.6$ & 0.76 \\
\hline \multicolumn{5}{|l|}{ Prosthesis size: } \\
\hline $23 \mathrm{~mm}$ & $15(9.6 \%)$ & $1(6.7 \%)$ & $14(9.9 \%)$ & \\
\hline $26 \mathrm{~mm}$ & $58(37.2 \%)$ & $4(26.7 \%)$ & $54(38.3 \%)$ & \\
\hline $29 \mathrm{~mm}$ & $69(44.2 \%)$ & $5(33.3 \%)$ & $64(45.4 \%)$ & \\
\hline $31 \mathrm{~mm}$ & $13(8.3 \%)$ & $4(26.7 \%)$ & $9(6.4 \%)$ & \\
\hline Major vascular complication & $10(6.4 \%)$ & $1(6.7 \%)$ & $9(6.4 \%)$ & 1 \\
\hline AR post-TAVI, grade $\geq 3$ & $9(5.8 \%)$ & $3(20.0 \%)$ & $6(4.3 \%)$ & 0.04 \\
\hline
\end{tabular}

Data are presented as mean \pm standard deviation or number (percentage). A p value of $<0.05$ is considered statistically significant; AR aortic regurgitation: CABG — coronary artery by-pass grafting: GFR — glomerular filtration rate; LVEF — left ventricular ejection fraction; $\mathrm{MR}$ - mitral regurgitation; NYHA - New York Heart Association; PCl — percutaneous coronary intervention; TAVI - transcatheter aortic valve implantation; TIA - transient ischemic attack
valual

\section{Calibration in high risk vs. non-high} risk group

The SURTAVI risk model showed best calibration with no significant difference between the number of expected and observed deaths in high-risk patients
(10.8\% vs. $9.4 \%, \mathrm{p}=0.982)$, whereas EuroSCORE I achieved best calibration in the non-high risk cohort (9.6\% vs. $8.6 \%, p=0.984)$. Detailed comparison of high-risk patients group vs. non-high risk patients group in each scale is presented in Figure 3. 


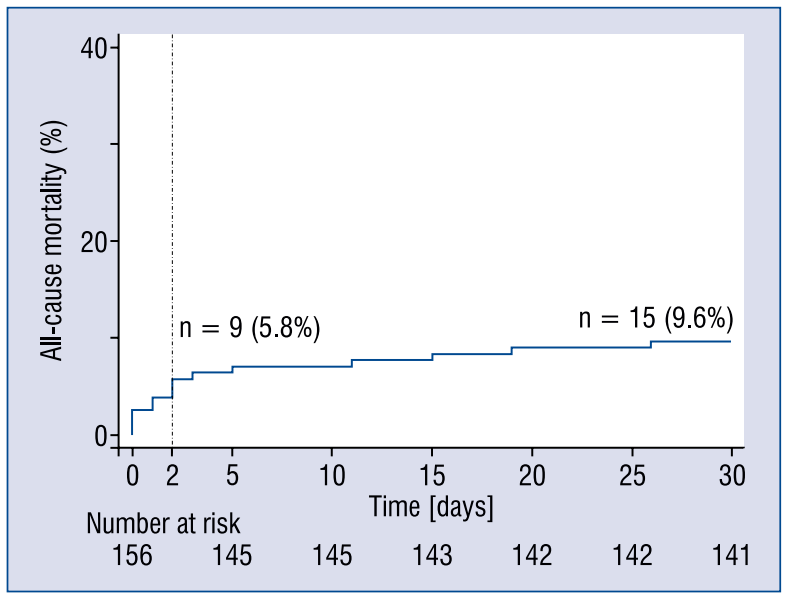

Figure 1. 30-day all-cause mortality across the entire cohort with the majority of events occurring during the first 2 days.

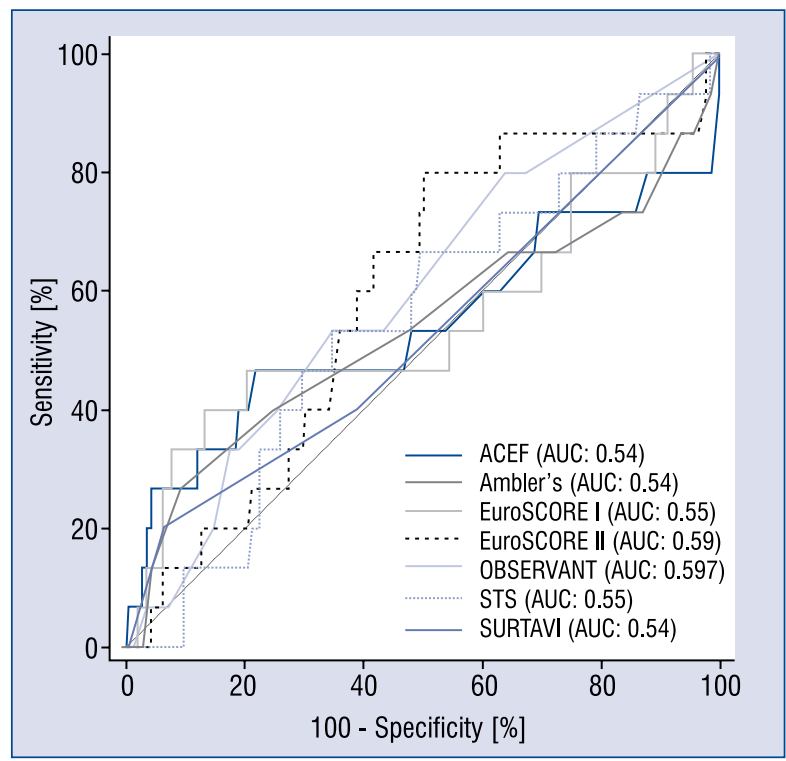

Figure 2. Discriminating ability of analyzed risk scores - comparison of receiver operating characteristics curves; AUC - area under the curve.

\section{Classification accuracy of risk models}

In terms of classification accuracy — ability to reliably discriminated between high vs. non-high risk patients at a predefined threshold - ACEF model performed best demonstrating biggest difference between observed mortality in high- vs. non-high-risk cohort ( $17.5 \%$ vs. $6.9 \%, \mathrm{p}=0.053)$. Detailed analysis of classification accuracy of all risk models is shown in Figure 4.

\section{Discussion}

Transcatheter aortic valve implantation is a rapidly emerging new standard of care among high and extreme risk patients with severe AS. However, optimal risk stratification in the decision-making process of patients' qualification for TAVI procedure continuously poses a challenge [4]. Although widely criticized by both surgeons [11] and cardiologists $[12,13]$, conventional surgical risk algorithms are still frequently used. Logistic EuroSCORE remains part of version 2012 of guidelines, even though it has been known to inaccurately estimate mortality (mainly overestimate) since 2008 [14-18]. In the need for better accuracy, newer scales were recently developed [5-9]. However, most of the scales were not subsequently validated in different populations, other than originally created on.

To the best of our knowledge, this has been the first paper simultaneously evaluating different (established vs. recently proposed, surgical vs. interventional) risk scores in a most inclusive fashion (7 models) in the Polish population of unselected TAVI patients. We found that none of the investigated scales proved even mediocre discrimination accuracy as c-statistic for any risk model did not exceed 0.6 threshold. Similarly, none of the models was accurately calibrated across the whole risk spectrum meaning that some were calibrated well only in high risk while others only in non-high risk group. Finally, all models failed in being able to accurately classify patients into high or non-high risk categories, however the simplest one (ACEF) was closest to reach statistical significance. Furthermore, univariate analysis of baseline and periprocedural characteristics identified 3 factors that occurred significantly more often in patients with an endpoint: $\mathrm{MR}$ grade $\geq 3$, GFR $<30 \mathrm{~mL} / \mathrm{min} / 1.73 \mathrm{~m}^{2}$ and AR post-TAVI grade $\geq 3$ - findings consistent with previously published observations [19-23].

Until now, few data exist on the head-to-head performance of different risk models in TAVI patients. Most of available papers compare predictive ability of logistic EuroSCORE and STS with recently developed EuroSCORE II, usually showing better efficacy of more refined EuroSCORE II $[13,24,25]$. Only few studies take into cosideration other scores. In 2013, D'Ascenzo et al. [26] reported poor discriminating ability of ACEF, based upon data from > 950 TAVI patients. In another paper, the SURTAVI model was deemed to be as inefficient in terms of classification accuracy as es- 

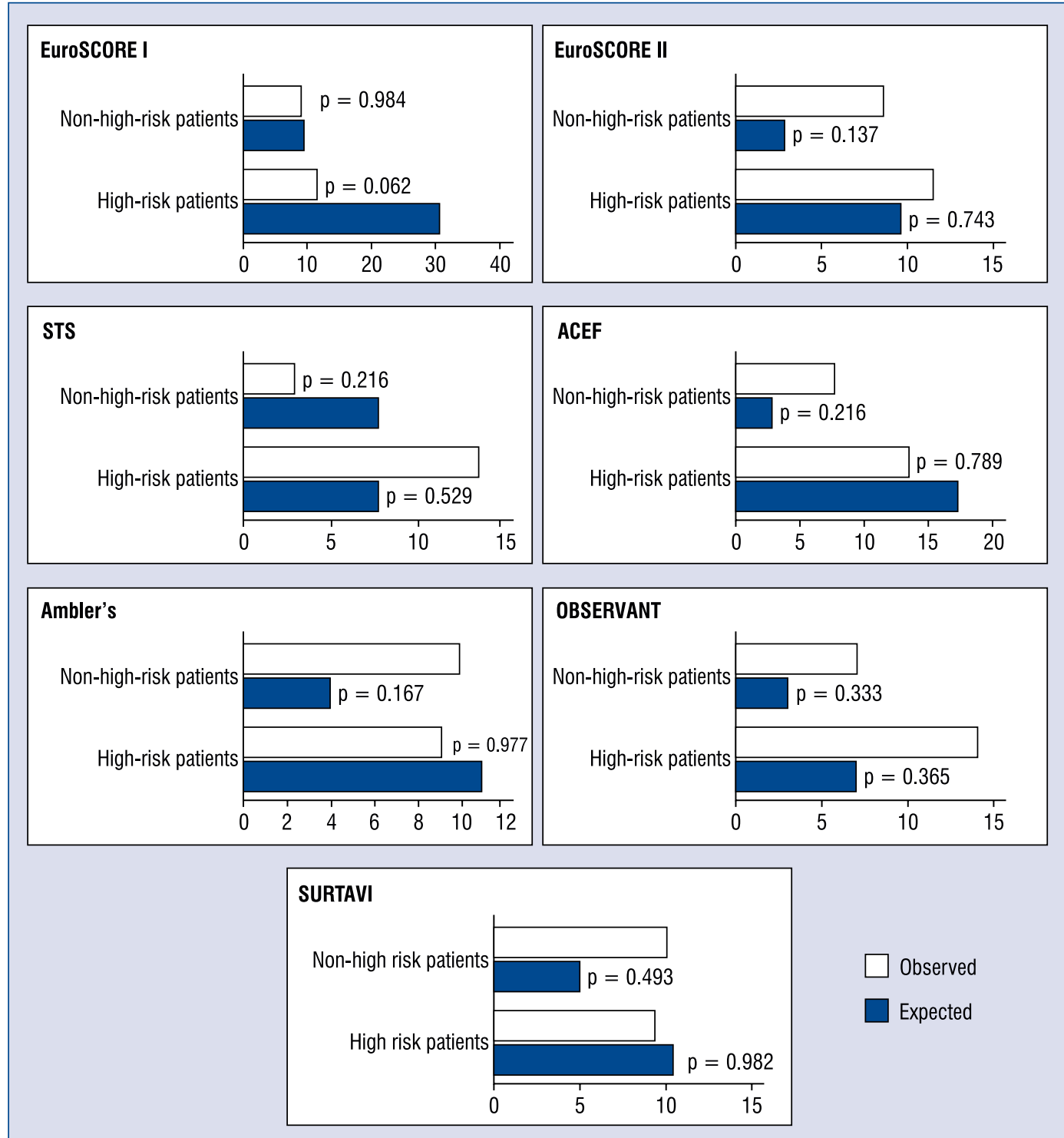

Figure 3. Calibration of risk scores - comparison of observed vs. predicted 30-day mortality in high- and non-high-risk groups.

tablished surgical risk models [27]. More recently, low discriminating ability of Ambler's score was documented [28]. Due to overall poor efficacy in the prediction of mortality, newer, specifically designed for TAVI scales were and still are in demand. In the present study, for the first time the authors compared conventional and unconventional surgical models with recently proposed TAVI-tailored scales. Only very modest if not poor differentiating ability of any of the studied models, irrespective if specifically designed for TAVI or surgical, was observed. In our opinion, this may be explained by lack of potentially important clinical (e.g. anemia, hypoalbuminemia, liver dysfunction) and anatomi- cal factors (e.g. porcelain aorta, calcium distribution on the native valve, delivery route morphology). It can be speculated that abovementioned clinical factors reflect poor general health status, which can affect early rehabilitation process. On the other hand, unfavorable anatomical conditions may represent unsurpassable barrier to successful prosthesis implantation even for an experienced operator with available device technology.

When considering a preferable feature of a given risk model, out of 3 main characteristics, namely: discriminating ability, calibration and classification accuracy, we stand on the position that the last one is the most clinically useful, as in the 

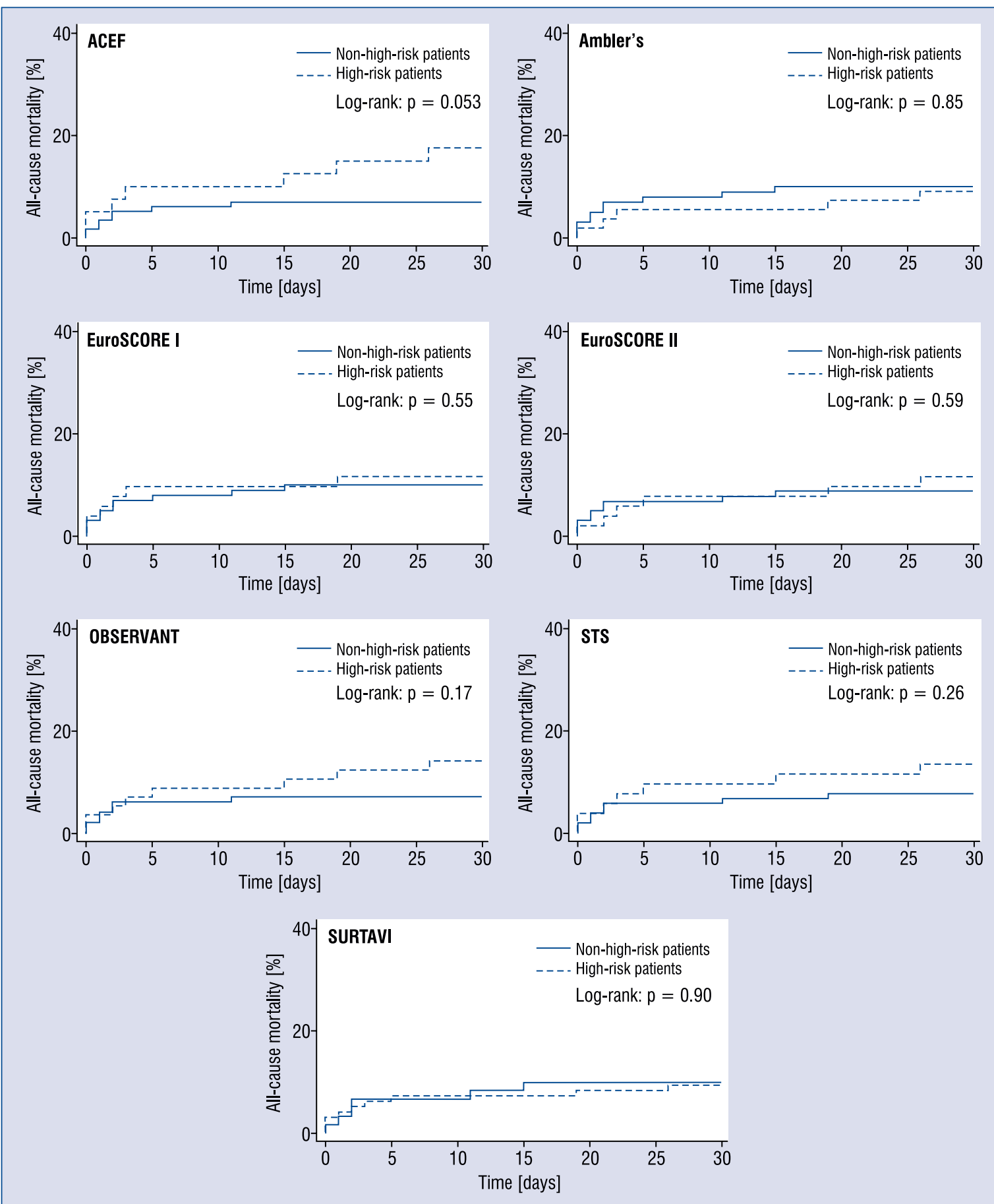

Figure 4. Classification accuracy of risk scores - comparison of observed 30-day mortality in high-risk vs. non-high-risk group.

referral for TAVI we have to reliably categorize patients into high or non-high risk groups. In this light, if we were to recommend one of the studied models, we would lean toward ACEF not only because of acceptable classification accuracy, but also due to its simplicity.

\section{Limitations of the study}

The main limitation of the present study is a small sample size and, therefore low number of events. This rendered Cox multivariate regression analysis impossible (according to the rule of thumb, that at least 10 outcomes are required for each 
independent variable in a multivariate model) as well as precluded more detailed subgroup examination and forced dichotomous cohort division (highvs. non-high-risk). Nevertheless, this analysis is based on one of the biggest TAVI populations in Poland. Additionally, information concerning frailty, necessary for SURTAVI categorization, was not available in some patients.

\section{Conclusions}

In conclusion, results of our study demonstrate that none of the risk models is optimal in predicting 30-day mortality in unselected, real-life population with AS referred to TAVI. None of the investigated scales proved to be significantly accurate in terms of discrimination, calibration and classification. These data support primary role of the heart team in decision process of selecting patients for TAVI.

\section{Conflict interest: None declared}

\section{References}

1. Vahanian A, Alfieri O, Andreotti F et al. Guidelines on the management of valvular heart disease (version 2012): The Joint Task Force on the Management of Valvular Heart Disease of the European Society of Cardiology (ESC) and the European Association for Cardio-Thoracic Surgery (EACTS). Eur Heart J, 2012; 33: 2451-2496. doi: 10.1093/ejcts/ezs455.

2. Roques F, Michel P, Goldstone AR, Nashef SA. The logistic EuroSCORE. Eur Heart J, 2003; 24: 882-883.

3. O'Brien SM, Shahian DM, Filardo G et al. The Society of Thoracic Surgeons 2008 cardiac surgery risk models: Part 2. Isolated valve surgery. Ann Thorac Surg, 2009; 88: S23-S42. doi: 10.1016/j.athoracsur.2009.05.056.

4. Bax JJ, Delgado V, Bapat V et al. Open issues in transcatheter aortic valve implantation. Part 1: Patient selection and treatment strategy for transcatheter aortic valve implantation. Eur Heart J, 2014; 35: 2627-2638. doi: 10.1093/eurheartj/ehu256.

5. Nashef SA, Roques F, Sharples LD et al. EuroSCORE II. Eur J Cardiothorac Surg, 2012; 41: 734-744. doi: 10.1093/ejcts/ezs043.

6. Ambler G, Omar RZ, Royston P et al. Generic, simple risk stratification model for heart valve surgery. Circulation, 2005; 112: 224-231.

7. Ranucci M, Castelvecchio S, Menicanti L et al. Risk of assessing mortality risk in elective cardiac operations: Age, creatinine, ejection fraction, and the law of parsimony. Circulation, 2009; 119: 3053-3061. doi: 10.1161/CIRCULATIONAHA.108.842393.

8. van Mieghem NM, Head SJ, van der Boon RM et al. The SURTAVI model: Proposal for a pragmatic risk stratification for patients with severe aortic stenosis. EuroIntervention, 2012; 8: 258-266.

9. Capodanno D, Barbanti M, Tamburino $\mathrm{C}$ et al. A simple risk tool (the OBSERVANT score) for prediction of 30-day mortality after transcatheter aortic valve replacement. Am J Cardiol, 2014; 113: 1851-1858. doi: 10.1016/j.amjcard.2014.03.014.

10. Nashef SA, Roques F, Michel P et al. European system for cardiac operative risk evaluation (EuroSCORE). Eur J Cardiothorac Surg, 1999; 16: 9-13.

11. Laurent M, Fournet M, Feit B et al. Simple bedside clinical evaluation versus established scores in the estimation of operative risk in valve replacement for severe aortic stenosis. Arch Cardiovasc Dis, 2013; 106: 651-660. doi: 10.1016/j.acvd.2013.09.001.
12. Tamburino C, Capodanno D, Ramondo A et al. Incidence and predictors of early and late mortality after transcatheter aortic valve implantation in 663 patients with severe aortic stenosis. Circulation, 2011; 123: 299-308. doi: 10.1161/CIRCULATIONAHA.110.946533.

13. Stähli BE, Tasnady H, Lüscher TF et al. Early and late mortality in patients undergoing transcatheter aortic valve implantation: Comparison of the novel EuroScore II with established risk scores. Cardiology, 2013; 126: 15-23. doi: 10.1159/000351438.

14. Grossi EA, Schwartz CF, Yu PJ et al. High-risk aortic valve replacement: Are the outcomes as bad as predicted? Ann Thorac Surg, 2008; 85: 102.

15. Wendt D, Osswald BR, Kayser K et al. Society of Thoracic Surgeons score is superior to the EuroSCORE determining mortality in high risk patients undergoing isolated aortic valve replacement. Ann Thorac Surg, 2009; 88: 468. doi: 10.1016/j. athoracsur.2009.04.059.

16. Osswald BR, Gegouskov V, Badowski-Zyla D et al. Overestimation of aortic valve replacement risk by EuroSCORE: Implications for percutaneous valve replacement. Eur Heart J, 2009; 30: 74. doi: 10.1093/eurhearti/ehn523.

17. Dewey TM, Brown D, Ryan WH et al. Reliability of risk algorithms in predicting early and late operative outcomes in high-risk patients undergoing aortic valve replacement. J Thorac Cardiovasc Surg, 2008; 135: 180. doi: 10.1016/j. jtcvs.2007.09.011.

18. Chmielak Z, Witkowski A, Dąbrowski M et al. Mid-term results of Transcatheter AorticValve Implantation (TAVI) in high-risk patients with Logistic EuroSCORE $\geq 20 \%$ in comparison with high-risk patients with Logistic EuroSCORE $<20 \%$. Kardiol Pol, 2016; 74, 224-230. doi: 10.5603/KP.a2015.0161.

19. Escárcega RO, Lipinski MJ, Baker NC et al. Analysis of long-term survival following transcatheter aortic valve implantation from a single high-volume center. Am J Cardiol, 2015; 116: 256-263. doi: 10.1016/j.amjcard.2015.04.016.

20. Bouleti C, Himbert D, Iung B et al. Long-term outcome after transcatheter aortic valve implantation. Heart, 2015; 101: 936-942. doi: 10.1136/heartjnl-2014-306694.

21. Kleczyński P, Zasada W, Bagieński M et al. Paravalvular leak after transcatheter aortic valve implantation (TAVI): Short-term results. Data from Polish national POL-TAVI registry. Cardiol J, 2016; 23: 163-168. doi: 10.5603/CJ.a2015.0071.

22. Jagielak D, Bramlage P, Pawlaczyk R et al. Transaortic transcatheter aortic valve implantation: Results of the Polish arm of the ROUTE registry. Cardiol J, 2015; 22: 651-656. doi: 10.5603/ CJ.a2015.0046.

23. Grygier M, Araszkiewicz A, Lesiak $\mathrm{M}$ et al. The new generation is coming. Percutaneous implantation of the fully repositionable Lotus $\circledR$ aortic valve prosthesis: The first Polish experience. Kardiol Pol, 2015; 73: 80-84. doi: 10.5603/KP.a2014.0191.

24. Arangalage D, Cimadevilla C, Alkhoder S et al. Agreement between the new EuroSCORE II, the Logistic EuroSCORE and the Society of Thoracic Surgeons score: Implications for transcatheter aortic valve implantation. Arch Cardiovasc Dis, 2014; 107: 353-360. doi: 10.1016/j.acvd.2014.05.002.

25. Johansson M, Nozohoor S, Zindovic I et al. Prediction of 30-day mortality after transcatheter aortic valve implantation: A comparison of logistic EuroSCORE, STS score, and EuroSCORE II. J Heart Valve Dis, 2014; 23: 567-574.

26. D'Ascenzo F, Ballocca F, Moretti C et al. Inaccuracy of available surgical risk scores to predict outcomes after transcatheter aortic valve replacement. J Cardiovasc Med (Hagerstown), 2013;14: 894-898. doi: 10.2459/JCM.0b013e3283638e26.

27. Hashmi IH, Hammad S, Rajagopal R et al. Is SURTAVI Risk Model a Step Towards 'TAVI Risk Score': Time to Rethink? Heart, 2013; 99: A86-A87. doi: 10.1136/heartjnl-2013-304019.146.

28. Silaschi M, Conradi L, Seiffert M et al. Predicting Risk in Transcatheter Aortic Valve Implantation: Comparative Analysis of EuroSCORE II and Established Risk Stratification Tools. Thorac Cardiovasc Surg, 2015; 63: 472-478. doi: 10.1055/s-00341389107. 